Part 1

Corrosion and

Corrosion Protection 



\section{SVET characterization of corrosion process in carbon steel 1020}
R. B. Vichessi ${ }^{1,2}$
C. E. B. Marino'
F. Calegari ${ }^{1,2}$
M. A. C. Berton ${ }^{2}$

\section{Abstract}

The study of corrosion process on metal surfaces has been widely conducted for several years, from classical nondestructive electrochemical techniques, such as Open Circuit Potential (OCP) and Electrochemical Impedance Spectroscopy (EIS). However, these techniques allow only the analysis of the global response of the electrochemical system, whereas the regions where localized corrosion occurs (pitting, crevice, passive film rupture, etc.) are left without identification.

One of the localized electrochemical techniques, the latter of these systems, named SVET (Electrochemical Technique Vibrating Electrode), allows an improved resolution and lower minimum detectable signal in the evaluation of the corrosion phenomena. This technique stands out because it allows mapping the exact location at separated sites in the metal/electrolyte interface where the anodic and cathodic processes take place enabling the distinction of the contribution of each event.

In this study, SVET technique was used to investigate the corrosion process of carbon steel in media containing chloride. Carbon steels are ferrous alloys made of iron and carbon, widely used in engineering and industry. The SVET results showed the evolution of corrosion process in function of time on steel sample. This recent electrochemical technique allowed the analysis and differentiation of intensity of oxidation reaction in different regions of the sample.

Keywords: SVET; carbon steel; corrosion.

1 Federal University of Paraná, Curitiba, Paraná, Brazil.

2 SENAI Institute of Innovation in Electrochemistry, Curitiba, Paraná, Brazil. 


\section{Introduction}

According to the World Steel Association, crude steel production has reached about 134.1 million tons in August 2016. (https://www.worldsteel.org) The Brazilian steel industry produced 2.8 thousand tons in the same period, of which carbon steels represents, approximately, $88 \%$ of the amount. (http://www.acobrasil.org.br/site/portugues/numeros/estatisticas.asp, 2016). Despite its limited corrosion resistance, carbon steels are the most widely used engineering material. Its employment occurs among the various industrial branches due to its relatively low cost and acceptable mechanical properties, such in marine applications, nuclear power plants, transportation, chemical processing, petroleum production, pipelines, mining, infrastructure and construction, and metal-processing equipment. Therefore, as can be expected, corrosion of carbon steel is a problem of enormous importance and the estimated costs in materials, equipment and services involved in the repair, maintenance and replacement can be measured in hundreds of millions of dollars per year. (Cramer et al., 2005)

To prevent corrosion or to have the ability to predict the outcome of a corrosion situation it is extremely important to interpret the mechanisms of the corrosion phenomena in which the interactions among many different reactions and conditions must be carefully investigated. (Cramer et al., 2005). Considering metallic corrosion as a complex process where corrosive species interact with local micro/nanometric cells formed on an active surface of the corroding metal, comprehensive understanding of mechanisms involved ideally requires in situ analyses in such scales. (Shi and Lyon; Souto et al., 2007)

For many years, the study of corrosion process on metal surfaces has been widely conducted from classical nondestructive electrochemical techniques, such as the measurement of "Open Circuit Potential" (OCP) (Bierwagen et al., 2010) and Electrochemical Impedance Spectroscopy (EIS). (Du et al., 2014) However, these techniques allow only the analysis of the global response of the electrochemical system and the regions where localized corrosion occur (pitting, crevice, passive film rupture, etc.) cannot be identified. (Akid and Mills, 2001) For this reason, the uses of local electrochemical techniques have been increasingly considered in the study of corrosion in metallic materials and have been a powerful tool in discovering information at micro/nano scales. (Akid and Garma, 2004)

Among the localized techniques, the latter of these systems, namely SVET (Electrochemical Technique Vibrating Electrode), allows improved resolution and a lower minimum detectable signal in the evaluation of corrosion phenomena. The technique stands out since it allows mapping the exact location where the anodic and cathodic processes take place at separate sites in the metal/electrolyte interface and, consequently, enable distinguish the contribution of each phenome- 
non. In other words SVET is used to quantify and map localized corrosion by the movement of a vibrating probe just above $(100 \mu \mathrm{m}$ or less) the sample surface. The analysis allows measuring and mapping the electric fields that are formed in the adjacent electrolyte as a result of localized electrochemical or corrosion activity. (Rossi et al., 2008)

The application of these technique is used to investigate many materials and material systems and finds application in studies of self-healing mechanisms in coatings (Shi and Lyon), efficiency of a variety of corrosion inhibitors, (Recloux et al., 2015) passive film rupture, (Li et al.) weld regions, (Wang et al., 2015) among others. Furthermore, SVET is also used in the investigation of different mechanisms of corrosion (pitting, crevice, ...) in many metallic materials such as aluminum alloys, (Moreto et al., 2014) copper, (Kong et al., 2016) stainless steel, (Krawiec et al., 2004) and so on. Coelho et al. employed SVET in order to evaluate the inhibitive effects of benzotriazole and cerium chloride, combined and solely, on the corrosion protection of an $\mathrm{Al} / \mathrm{Cu}$ galvanic coupling. (Coelho et al., 2016) SVET technique was used by Yan et al. to evaluate the protection performance of the polypyrrole Al flake coating. (Yan et al., 2013) Chen et al. reviewed the application of the technique for the detection and monitoring of microbiologically influenced corrosion. (Chen et al., 1997)

This paper aims to investigate corrosion phenomena ensured by the practice of localized electrochemical technique SVET. The technique was used do investigate the corrosion process of carbon steel in media containing chloride. Representatively, the carbon steel substrate used in the corrosion studies was the AISI 1020 steel. The equipment used was VersaSCAN, a new electrochemical microscope on the market giving independent potential gradient results of the probe-sample distance. The SVET results showed the evolution of corrosion process in function of the time on steel sample.

\section{Experimental procedure}

To prepare the sample, plates of carbon steel AISI 1020 were treated with grit sand papers from 400 to 1200 mesh grade, sequentially, and then polish with alumina suspension $1.0 \mu \mathrm{m}$. After the polishment, the sample was rinsed with distilled water and dried with nitrogen gas.

Electrochemical microscope to measure the local potential gradient was the VersaScan SVET module from Princenton Applied Research (USA), using a Pt/Ir microprobe. The active tip was about $2 \mu \mathrm{m}$ of diameter and inside the head of the SVET probe there were two resistors and one capacitor wired. The amplitude of vibration was about $40 \mu \mathrm{m}$ and the vibration frequency was $80 \mathrm{~Hz}$ along the $\mathrm{Z}$ direction. The setup parameters (area of surface analyzed, scan type, number of 
steps, time, etc.) were controlled by the VersaScan Sofware (Princenton Applied Research), which generates the potential gradient values. A video camera was used to assist in bringing the probe to the surface.

All the experiments were performed above the surface in $0.05 \mathrm{M} \mathrm{NaCl}$ solution ( $\mathrm{pH} 6.8$ and conductivity $5.18 \mathrm{mS} \mathrm{cm}^{-1}$ ), at open circuit. A tubular electrode of graphite was used as the counter electrode and ground.

\section{Results and discussion}

Corrosion reactions produce two distinct regions on metallic surfaces: anodic and cathodic zones. (Akid, 2004) These zones could be considered as point charges which produce ionic currents and respective electric fields. (Bastos, 2013) The SVET technique measures the potential gradient in electric field, as Figure 1 shows.

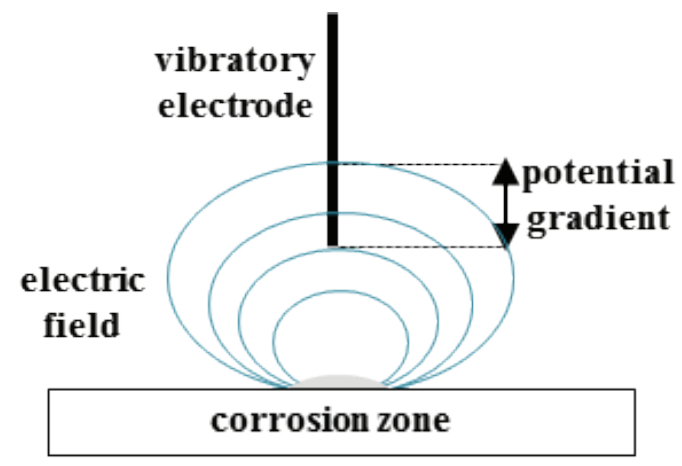

Figure 1 Principle of SVET measurement of the gradient potential in the corrosion processes.

In this format, the probe is perpendicular to the sample and the current density can be calculated considering the values of potential gradient (), solution conductivity () and vibration amplitude () from the SVET output as (Bastos, 2013):

$$
i=-\sigma \frac{\partial V}{\partial l}
$$

Therefore, negative and positive gradient potential data represent anodic and cathodic sites, respectively.

The signal conditioning values were studied previously to guarantee two characteristics in the SVET results: sensitivity and resolution. According to Akid and Garma, the sensitivity is the ability to determine very small corrosion currents originated on localized regions while resolution is the ability to distinguish between two anodic sites close to each other. (Akid, 2004) After the signal conditioning, a small opaque region was observed at 30 minutes of sample immersion. 
Figure 2 presents the potential gradient measurement performed on this region along axis $\mathrm{X}$ and its respective current density values.
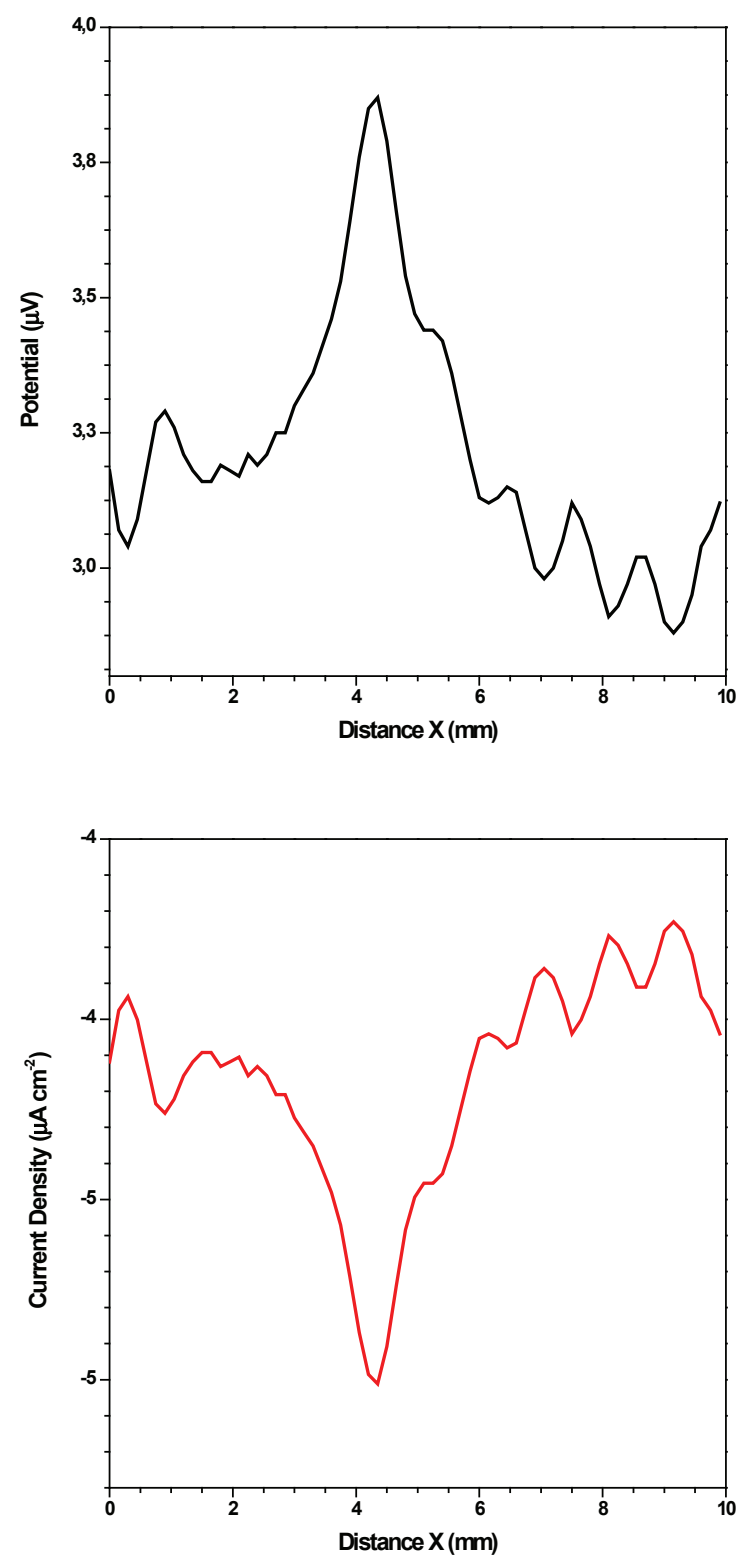

Figure 2 Potential gradient and respective current density profiles of carbon steel after $30 \mathrm{~min}$ of immersion in $0.05 \mathrm{M} \mathrm{NaCl}$.

The results showed negative density current values on the analyzed opaque region. This region can be associated to the corrosion process that is portrayed by a 
thin metal oxide film. At $\mathrm{pH} 6.8$, iron oxides are unstable and the oxidation process continues to act on the material. (Cramer et al., 2005) Figure 3 shows the image of the sample immersed in corrosive media after $3.5 \mathrm{~h}$ and respective SVET maps.

(a)

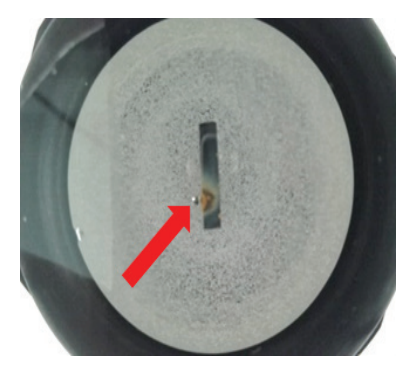

(b)
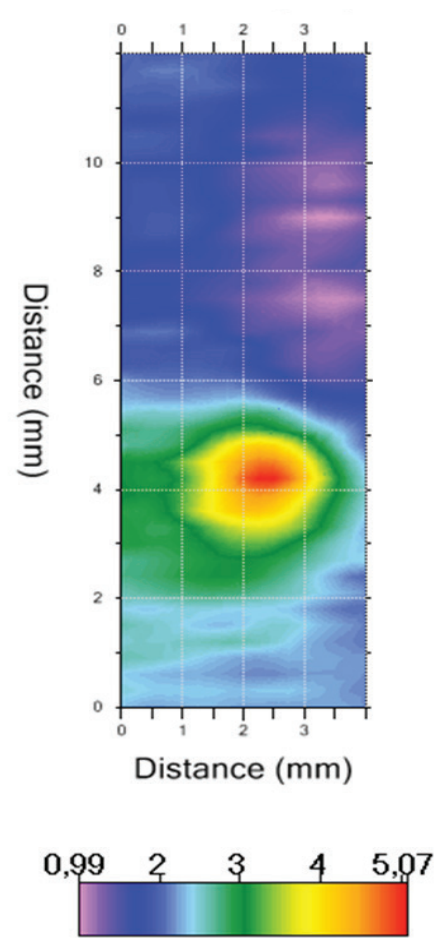

Potential Gradient $(\mu \mathrm{V})$

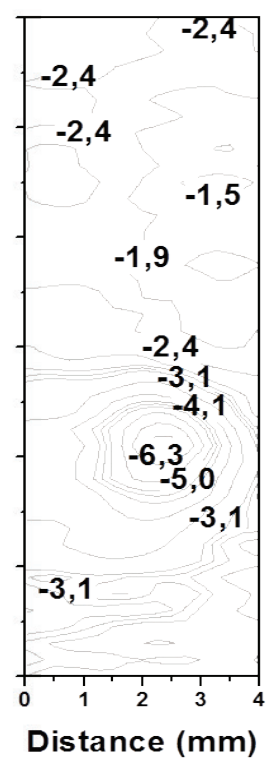

\section{Density Current $\left(\mu \mathrm{A} \mathrm{cm} \mathrm{cm}^{-2}\right)$}

Figure 3 Image of carbon steel electrode after $3.5 \mathrm{~h}$ immersion in $0.05 \mathrm{M} \mathrm{NaCl}$ (a) and respective SVET maps (b).

Two distinct areas were visualized on the SVET map. The increase of cathodic currents was observed near to the region covered by the oxide film, as seen on 
Figure 2, due to the corrosion products acting as a physical barrier to the process. (Falcón, 2014) On the other hand, uncovered region of metal showed less negative values associated to the new active corrosion zone. The semi-reactions related to the corrosion process on carbon steel 1020 in this conditions are:

$$
\begin{gathered}
\text { anodic reaction: } \mathrm{Fe}_{(\mathrm{s})} \rightarrow \mathrm{Fe}^{2+}{ }_{(\mathrm{aq})}+2 \mathrm{e}^{-}(\mathrm{m}) \\
\text { cathodic reaction: } \mathrm{O}_{2}(\mathrm{aq})+\mathrm{H}_{2} \mathrm{O}+4 \mathrm{e}^{-}{ }_{(\mathrm{m})} \rightarrow 4 \mathrm{OH}_{(\mathrm{aq})}^{-}
\end{gathered}
$$

Futhermore, there are other reactions that could produce the unstable oxides at media, as:

$$
\begin{gathered}
\mathrm{Fe}^{2+}{ }_{(\mathrm{aq})}+\mathrm{OH}_{(\mathrm{aq})}^{-} \rightarrow \mathrm{Fe}(\mathrm{OH})_{2(\mathrm{~s})} \\
2 \mathrm{Fe}(\mathrm{OH})_{2(\mathrm{~s})}+\mathrm{H}_{2} \mathrm{O}+1 / 2 \mathrm{O}_{2} \rightarrow 2 \mathrm{Fe}(\mathrm{OH})_{3(\mathrm{~s})}
\end{gathered}
$$

After $71 \mathrm{~h}$ of immersion in corrosive media, it was observed that the sample was almost completely covered by oxide products. The SVET results obtained after this period are presented by Figure 4.
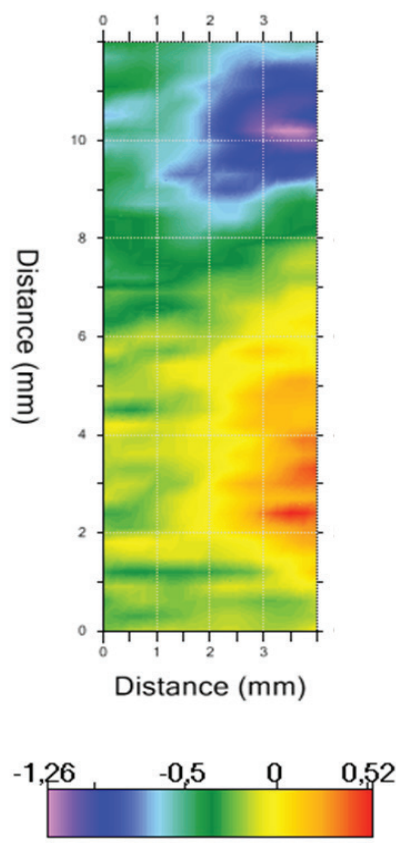

Potential Gradient $(\mu \mathrm{V})$

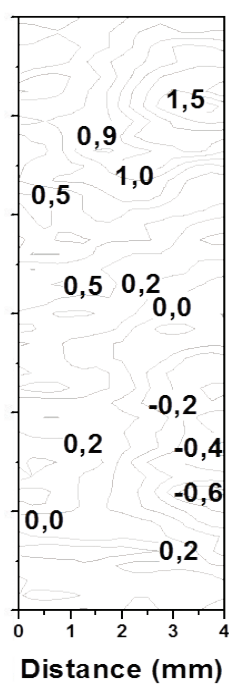

Density Current $\left(\mu \mathrm{A} \mathrm{cm} \mathrm{cm}^{-2}\right)$

Figure 4 SVET maps of carbon steel after $71 \mathrm{~h}$ of immersion in $0.05 \mathrm{M} \mathrm{NaCl}$. 
An anodic zone was detected by positive density current at the upper portion of sample and it is associated to the increase of corrosion activity. On the other hand, lower values were observed at the inferior part of the sample, as show on Figure 3, confirming the spread of the oxide film along the sample. This fact could be explained by the resistive behavior of corrosion products which decelerates the process.

The obtained results agree with behavior presented by others authors (Bastos, 2006) (Falcón, 2014) (Pagotto, 2015). The AISI 1020 steel corrosion process is commonly reported by authors that study anti-corrosion coatings or weld heat treatment. The current density values observed were smaller, in order of magnitude, than the ones found in researched literature. Opposite to the equipment used by other authors, the operation mode of the VersaScan do not allow the user to determine the exact probe-sample distance. Although the independence of the potential gradient measurement in function of the distance, Akid and Garma demonstrated that the maximum output potential is found using small probe-sample distances, for constant vibration amplitude.

\section{Conclusion}

In this study, by using the SVET technique, it was possible to follow the corrosion process on carbon steel 1020 by gradient potential measurements and the respective current density values. The corrosion process on carbon steel 1020 was characterized, proving that the new SVET equipment, even though new on the market, can be used for this purpose. This study is important to complement a gap on the literature since there are no related reports using carbon steel without coating or other anti-corrosion treatment.

\section{References}

AKID, R.; GARMA, M. Scanning vibrating reference electrode technique: a calibration study to evaluate the optimum operating parameters for maximum signal detection of point source activity. Electrochimica Acta, v. 49, n. 17-18, p. 2871-2879, 2004.

AKID, R.; MILLS, D. J. A comparison between conventional macroscopic and novel microscopic scanning electrochemical methods to evaluate galvanic corrosion. Corrosion Science, v. 43, n. 7, p. 1203-1216, 2001.

BASTOS, A. C. A. F., M. G. AND SIMÕES, A. M. Corrosion inhibition by chromate and phosphate extracts for iron substrates studied by EIS and SVET. Corrosion Science, v. 48, n. 6, p. 1500--1512, 2006. 
BASTOS, A. C. D., S.A.S, DIAMANTINO, T.C., FERREIRA, M.G.S. Uma Introdução À Técnica SVET. Corrosão e Proteção de materiais, v. 32, n. 1, p. 50-57, 2013.

BIERWAGEN, G. et al. Active metal-based corrosion protective coating systems for aircraft requiring no-chromate pretreatment. Progress in Organic Coatings, v. 68, n. 1-2, p. 48-61, 2010.

CHEN, G.; PALMER, R. J.; WHITE, D. C. Instrumental analysis of microbiologically influenced corrosion. Biodegradation, v. 8, n. 3, p. 189-200, 1997.

COELHO, L. B. et al. A SVET study of the inhibitive effects of benzotriazole and cerium chloride solely and combined on an aluminium/copper galvanic coupling model. Corrosion Science, v. 110, p. 143-156, 2016.

CRAMER, S. D.; COVINO, B. S.; MOOSBRUGGER, C. ASM Handbook Volume 13b: Corrosion: Materials. Ohio: ASM, 2003.

DU, X.-Q. et al. Galvanic corrosion behavior of copper/titanium galvanic couple in artificial seawater. Transactions of Nonferrous Metals Society of China, v. 24, n. 2, p. 570-581, 2014.

FALCÓN, J. M.; BATISTA, F.F.; AOKI, I.V. Encapsulation of dodecylamine corrosion inhibitor on silica nanoparticles. Electrochimica Acta, v. 124, p. 109118, 2014.

http://www.acobrasil.org.br/site/portugues/numeros/estatisticas.asp. Accessed on: 02/09/2016.

https://www.worldsteel.org. Accessed on: 02/09/2016.

KONG, D.-C. et al. Copper corrosion in hot and dry atmosphere environment in Turpan, China. Transactions of Nonferrous Metals Society of China, v. 26, n. 6, p. 1721-1728, 2016.

KRAWIEC, H.; VIGNAL, V.; OLTRA, R. Use of the electrochemical microcell technique and the SVET for monitoring pitting corrosion at $\mathrm{MnS}$ inclusions. Electrochemistry Communications, v. 6, n. 7, p. 655-660, 2004.

LI, S. et al. Passivation and potential fluctuation of $\mathrm{Mg}$ alloy $\mathrm{AZ31B}$ in alkaline environments. Corrosion Science, In press: August 2016. 
MORETO, J. A. et al. SVET, SKP and EIS study of the corrosion behaviour of high strength $\mathrm{Al}$ and $\mathrm{Al}-\mathrm{Li}$ alloys used in aircraft fabrication. Corrosion Science, v. 84, p. $30-41,2014$.

PAGOTTO, J.F. et al. Visualization of the galvanic effects at welds on carbon steel. Journal of The Brazilian Chemical Societt, v.26, n.4, p. 667-675, 2015.

RECLOUX, I. et al. Silica mesoporous thin films as containers for benzotriazole for corrosion protection of $\mathbf{2 0 2 4}$ aluminium alloys. Applied Surface Science, v. 346, p. 124-133, 2015.

ROSSI, S. et al. Localized electrochemical techniques: Theory and practical examples in corrosion studies. Comptes Rendus Chimie, v. 11, n. 9, p. 984-994, 2008.

SHI, W.; LYON, S. B. Investigation using localised SVET into protection at defects in epoxy coated mild steel under intermittent cathodic protection simulating inter-tidal and splash zones. Progress in Organic Coatings, In Press: May 2016.

SOUTO, R. M. et al. Investigating corrosion processes in the micrometric range: A SVET study of the galvanic corrosion of zinc coupled with iron. Corrosion Science, v. 49, n. 12, p. 4568-4580, 2007.

WANG, S. et al. Characterization of low alloy ferritic steel-Ni base alloy dissimilar metal weld interface by SPM techniques, SEM/EDS, TEM/EDS and SVET. Materials Characterization, v. 100, p. 50-60, 2015.

YAN, M.; VETTER, C. A.; GELLING, V. J. Corrosion inhibition performance of polypyrrole Al flake composite coatings for Al alloys. Corrosion Science, v. 70, p. 37-45, 2013. 